\title{
Marked improvement of oral intake with nivolumab monotherapy in a patient with microsatellite instability-high gastric cancer with insufficient oral intake
}

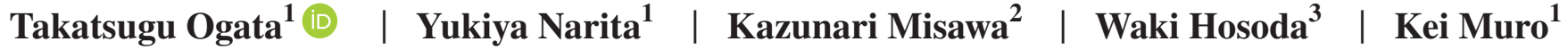

\author{
${ }^{1}$ Department of Clinical Oncology, Aichi \\ Cancer Center Hospital, Aichi, Japan \\ ${ }^{2}$ Department of Surgery, Aichi Cancer \\ Center Hospital, Aichi, Japan \\ ${ }^{3}$ Department of Pathology and Molecular \\ Diagnostics, Aichi Cancer Center Hospital, \\ Aichi, Japan

\section{Correspondence} \\ Takatsugu Ogata and Yukiya Narita, \\ Department of Clinical Oncology, Aichi \\ Cancer Center Hospital, 1-1, Kanokoden, \\ chikusa-ku, Nagoya, Aichi, Japan. \\ Emails: t.ogata@aichi-cc.jp (T. O.); yukiya. \\ narita@aichi-cc.jp (Y. N.)
}

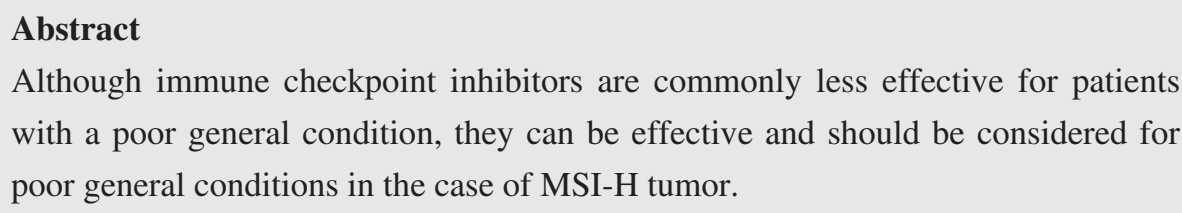

\section{K E Y W O R D S}

advanced gastric cancer, high microsatellite instability, immune checkpoint inhibitors, insufficient oral intake

\section{INTRODUCTION}

We report herein the case of marked improvement of oral intake via third-line nivolumab monotherapy in a gastric cancer patient with insufficient oral intake and European Cooperative Oncology Group performance status 2. We should consider immune checkpoint inhibitors for microsatellite instability-high gastric cancer, regardless of the patient's general condition.

Gastric cancer has one of the worst prognoses among all cancer types. Gastrointestinal obstruction due to primary obstruction or peritoneal metastasis is a common complication of advanced gastric cancer. Patients with gastrointestinal obstruction often experience insufficient oral intake, and these patients tend to have worse prognosis. In the JCOG0106 study, ${ }^{1}$ sufficient or insufficient oral intake was defined based on whether drip infusion for nutrition support was performed, and the improvement of oral intake was defined as drip infusion not being indicated for $>7$ days in patients who previously had insufficient oral intake. Some studies have shown improvement of oral intake with systemic chemotherapy, but these studies were in patients receiving firstor second-line treatment. ${ }^{1-7}$ There have been no published cases of improvement of oral intake with third- or later-line chemotherapy.

Immune checkpoint inhibitors (ICIs) have become widely used for the treatment of various cancers. Nivolumab monotherapy for heavily pretreated gastric cancer was approved as a third- or later-line treatment in Japan in September 2017. However, according to the ATTRACTION-2 study, the response was very limited. ${ }^{8}$ Further, although there are some reports of good response to ICIs in gastric cancer patients, there is no report on the improvement of oral intake by nivolumab monotherapy. ${ }^{9}$

To our best knowledge, the current case is the first report of marked improvement of oral intake by third-line nivolumab monotherapy in a gastric cancer patient with insufficient oral intake.

This is an open access article under the terms of the Creative Commons Attribution License, which permits use, distribution and reproduction in any medium, provided the original 


\section{2 | CASE HISTORY}

A 76-year-old woman presented to our hospital with a stomachache and loss of appetite for 3 months. She was admitted with insufficient oral intake for careful examination and treatment. She had rheumatoid arthritis treated with methotrexate.

\section{1 | Differential diagnosis, investigations, and treatment}

Physical examination revealed no significant findings. The laboratory data on admission are summarized in Table 1. Computed tomography (CT) revealed gastric wall thickening, invasion of the abdominal wall, and regional lymphadenopathy (Figure 1A). Gastrointestinal endoscopy (GIE) revealed Bormann type 3 gastric cancer (Figure 2A). Biopsy of the gastric mucosa showed poorly differentiated adenocarcinoma (Figure 3A, 3B). Immunohistochemical analysis (HercepTest, Dako, Glostrup, Denmark) showed no expression of human epidermal growth factor receptor 2 (score $=0$ ), and HER2/neu amplification was confirmed negative using dual color in situ hybridization (INFORM HER2 Dual ISH DNA Probe Cocktail Assay). ${ }^{10}$ The Epstein-Barr encoding region in situ hybridization was also negative (Figure 3C). ${ }^{11}$ Programmed death-ligand 1 (PD-L1) protein expression on adenocarcinoma cells was assessed using PD-L1 IHC 22C3 pharmDx (Agilent Technologies; Carpinteria, CA, USA), and the combined positive score (CPS) was 10 (Figure 3D). ${ }^{12}$ Microsatellite instability was high (MSI-IVD Kit, FALCO ${ }^{\circledR}$ ). Therefore, she was diagnosed with unresectable advanced microsatellite instability-high (MSI-H) gastric cancer. ${ }^{12}$

She underwent gastrojejunal bypass surgery in July 2017, but her oral intake did not sufficiently improve. Therefore, total parenteral nutrition (TPN) was started. A month after the bypass, mFOLFOX6 therapy (oxaliplatin $85 \mathrm{mg} / \mathrm{m}^{2}$ intravenous [IV], $l$-leucovorin $200 \mathrm{mg} / \mathrm{m}^{2} \mathrm{IV}$, and 5-fluorouracil $400 \mathrm{mg} / \mathrm{m}^{2}$ IV bolus followed by $2400 \mathrm{mg} / \mathrm{m}^{2}$ over 46 hours starting on Day 1, every 2 weeks) was started as first-line treatment. However, CT revealed disease progression after six cycles. Paclitaxel therapy (paclitaxel $80 \mathrm{mg} /$ $\mathrm{m}^{2}$ on days 1,8 , and 15 every month) as second-line treatment was also ineffective at the first evaluation after 3 cycles. Her general condition did not improve, and she needed TPN after progression on paclitaxel therapy. Although her Eastern Cooperative Oncology Group (ECOG) performance status (PS) was 2, nivolumab monotherapy $\left(3 \mathrm{mg} / \mathrm{m}^{2}\right.$ every 2 weeks until October 2018 and $240 \mathrm{mg} /$ body every 2 weeks from November 2018) was administered as third-line treatment. Laboratory tests, CT, and GIE before the first administration
TA B LE 1 Laboratory data on admission

\begin{tabular}{|c|c|c|}
\hline Hematology & & Normal range \\
\hline White blood cells & $8570 / \mu \mathrm{L}$ & $3300-8600 / \mu \mathrm{L}$ \\
\hline Neutrophils & $82.3 \%$ & \\
\hline Eosinophils & $0.5 \%$ & \\
\hline Basophils & $0.2 \%$ & \\
\hline Monophils & $5.3 \%$ & \\
\hline Lymphocytes & $11.7 \%$ & \\
\hline Red blood cells & $321 \times 10^{4} / \mu \mathrm{L}$ & $386-492 \times 10^{4} / \mu \mathrm{L}$ \\
\hline Hemoglobin & $8.7 \mathrm{~g} / \mathrm{dL}$ & $11.6-14.8 \mathrm{~g} / \mathrm{dL}$ \\
\hline Platelets & $30.2 \times 10^{4} / \mu \mathrm{L}$ & $15.8-34.8 \times 10^{4} / \mu \mathrm{L}$ \\
\hline Coagulation & & Normal range \\
\hline PT & $91.6 \%$ & $80.0 \%-120.0 \%$ \\
\hline APTT & $28.8 \mathrm{sec}$ & $25.0-38.0 \mathrm{sec}$ \\
\hline Fibrinogen & $517.6 \mathrm{mg} / \mathrm{dL}$ & $200.0-400.0 \mathrm{mg} / \mathrm{dL}$ \\
\hline Biochemistry & & Normal range \\
\hline Total protein & $5.1 \mathrm{~g} / \mathrm{dL}$ & $6.7-8.3 \mathrm{~g} / \mathrm{dL}$ \\
\hline Albumin & $2.3 \mathrm{~g} / \mathrm{dL}$ & $4.0-5.0 \mathrm{~g} / \mathrm{dL}$ \\
\hline Total bilirubin & $0.3 \mathrm{mg} / \mathrm{dL}$ & $0.3-1.2 \mathrm{mg} / \mathrm{dL}$ \\
\hline AST & $15 \mathrm{U} / \mathrm{L}$ & 13-33 U/L \\
\hline ALT & $6 \mathrm{U} / \mathrm{L}$ & 6-27 U/L \\
\hline LDH & $217 \mathrm{U} / \mathrm{L}$ & $119-229 \mathrm{U} / \mathrm{L}$ \\
\hline BUN & $13 \mathrm{mg} / \mathrm{dL}$ & $8-22 \mathrm{mg} / \mathrm{dL}$ \\
\hline Creatinine & $0.46 \mathrm{mg} / \mathrm{dL}$ & $0.40-0.70 \mathrm{mg} / \mathrm{dL}$ \\
\hline $\mathrm{Na}$ & 139 mmol/L & $138-146$ mmol/L \\
\hline K & $4.0 \mathrm{mmol} / \mathrm{L}$ & 3.6-4.9 mmol/L \\
\hline $\mathrm{Ca}$ & $8.0 \mathrm{mg} / \mathrm{dL}$ & $8.7-10.3 \mathrm{mg} / \mathrm{dL}$ \\
\hline CRP & $3.71 \mathrm{mg} / \mathrm{dL}$ & $<0.30 \mathrm{mg} / \mathrm{dL}$ \\
\hline Tumor markers & & Normal range \\
\hline CEA & $2.3 \mathrm{ng} / \mathrm{mL}$ & $<5.0 \mathrm{ng} / \mathrm{mL}$ \\
\hline CA19-9 & $42.2 \mathrm{U} / \mathrm{mL}$ & $<37.0 \mathrm{U} / \mathrm{mL}$ \\
\hline CA125 & $61.0 \mathrm{U} / \mathrm{mL}$ & $<26.9 \mathrm{U} / \mathrm{mL}$ \\
\hline
\end{tabular}

Abbreviations: ALT, alanine aminotransferase; APTT, activated partial thromboplastin time; AST, aspartate aminotransferase; BUN, blood urea nitrogen; Ca, calcium; CA125, cancer antigen 125; CA19-9, carbohydrate antigen 19-9; CEA, carcinoembryonic antigen; CRP, C-reactive protein; K, potassium; $\mathrm{LDH}$, lactate dehydrogenase; $\mathrm{Na}$, sodium; $\mathrm{PT}$, prothrombin time.

of nivolumab are summarized in Table 2 , Figure $1 \mathrm{~B}$, and Figure 2B.

\section{2 | Outcome and follow-up}

After four cycles of nivolumab, CT showed that the tumor had shrunk significantly. Her ECOG PS improved from 2 to 0 . After 6 months, her oral intake problem had completely improved, and TPN was no longer needed. Upper gastrointestinal endoscopy indicated tumor shrinkage (Figure 2C). 
(A)
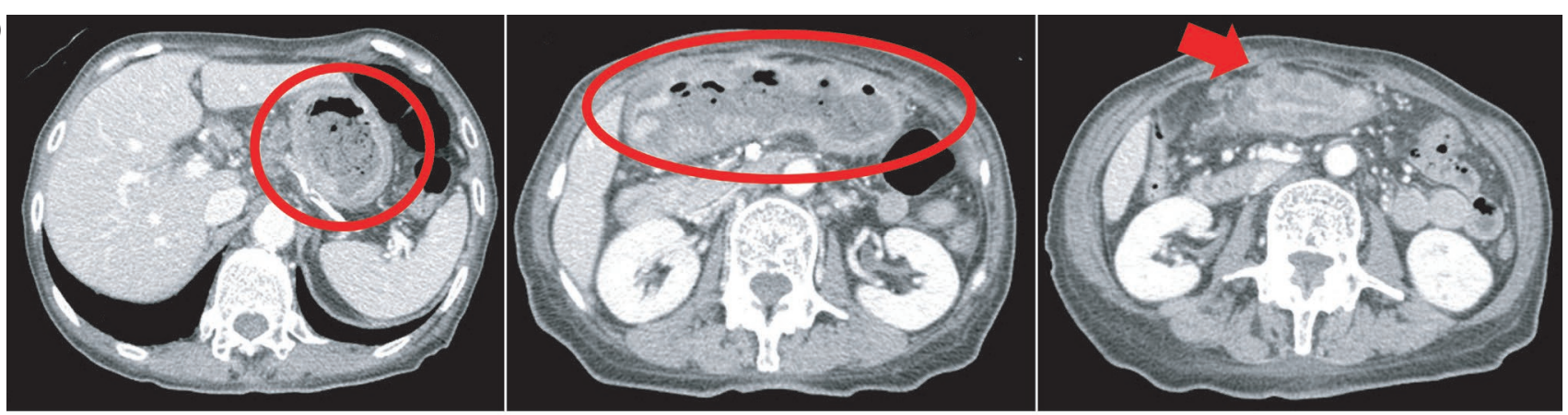

(B)
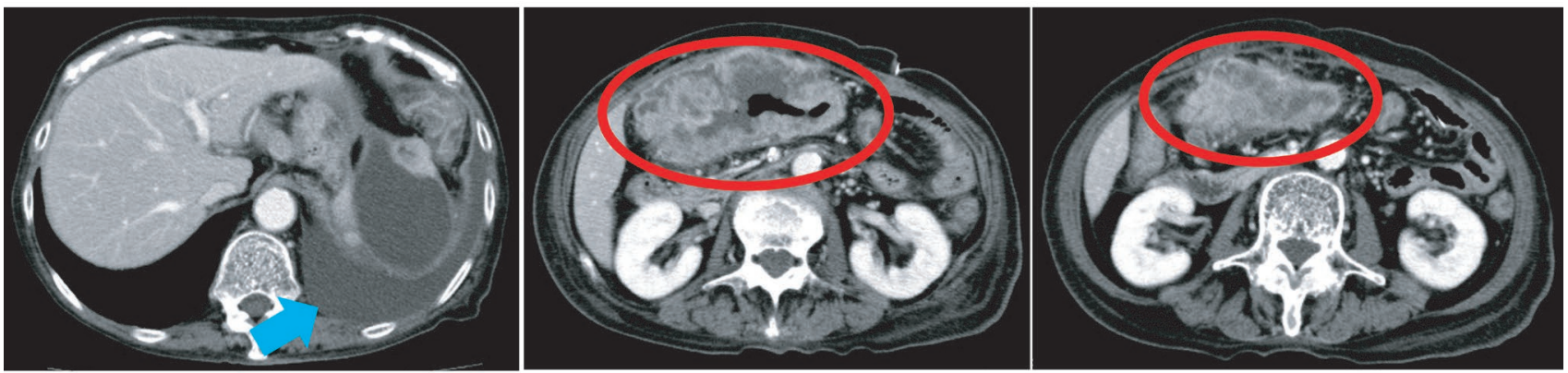

(C)
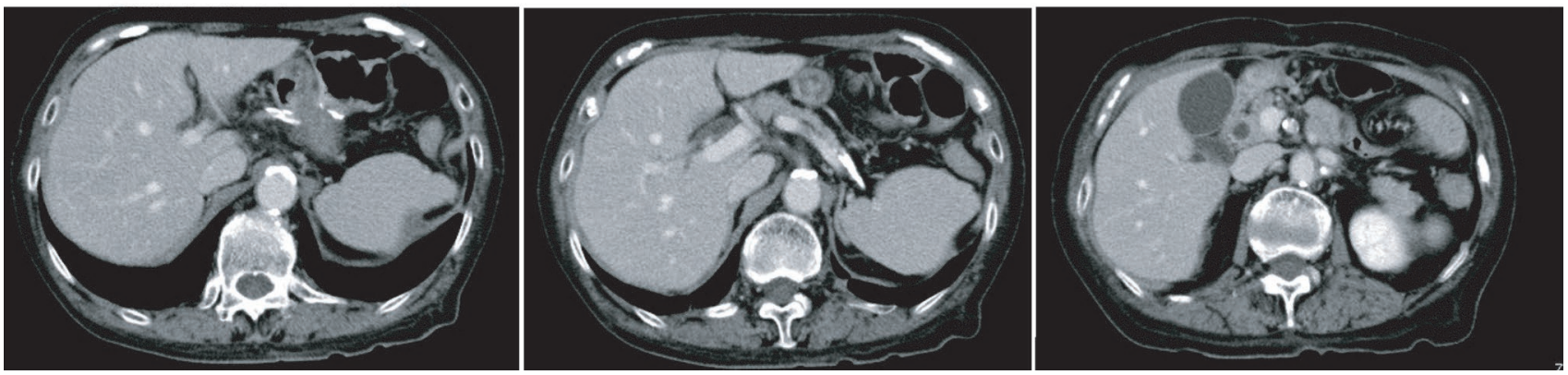

F I G U R E 1 Computed tomography results. (A) At diagnosis: gastric wall thickening (red circle), invasion of the abdominal wall, and regional lymphadenopathy (red arrow). (B) Before nivolumab monotherapy: gastric wall thickening (red circle), invasion of the abdominal wall, regional lymphadenopathy, and pleural effusion (blue arrow). (C) Two years after nivolumab monotherapy: complete response

CT and upper gastrointestinal endoscopy revealed no residual tumor 2 years after the surgery (Figures 1C and 2D). These findings support that nivolumab monotherapy caused a complete response. She is currently receiving nivolumab monotherapy and has sufficient oral intake (Figure 4).

Facial paralysis occurred 7 months after nivolumab administration, and we diagnosed it as Bell's paralysis not related to nivolumab. She developed grade 1 liver dysfunction and grade 1 diarrhea as immune-related adverse events (irAEs).

\section{3}

\section{DISCUSSION}

We report herein a case of marked improvement of oral intake by third-line nivolumab monotherapy in a patient with MSI-H gastric cancer with insufficient oral intake. The first- and second-line treatments were not effective, but she achieved a complete improvement of oral intake with nivolumab and had a complete tumor response after nivolumab monotherapy. To our best knowledge, this is the first case report on improved oral intake from third-line nivolumab therapy.

Insufficient oral intake is one of the most common complications of gastric cancer. The main causes of insufficient oral intake are gastric outlet obstruction and peritoneal metastasis. Insufficient oral intake is a poor prognostic factor, and Shitara et al reported that the median overall survival (OS) was significantly shorter in patients with insufficient oral intake than in those with sufficient oral intake (5.0 months vs. 12.7 months, $P<.05){ }^{3}$ In previous studies, the rate of improvement of oral intake with first-line treatment was 32\%$85 \%$ (Table 3). ${ }^{1-7}$ Platinum-containing regimens seem to be more effective than platinum-free regimens for the improvement of oral intake (Table 3). However, there are no reports of improvement of oral intake in patients receiving third- or 
FIGURE 2 Upper gastrointestinal endoscopy results. (A) At diagnosis: Bormann type 3 gastric cancer was observed. (B) Before nivolumab monotherapy: disease progression. (C) Six months after nivolumab monotherapy: tumor shrinkage. (D) Two years after nivolumab monotherapy: complete response (endoscopic biopsy revealed no residual tumor cells)
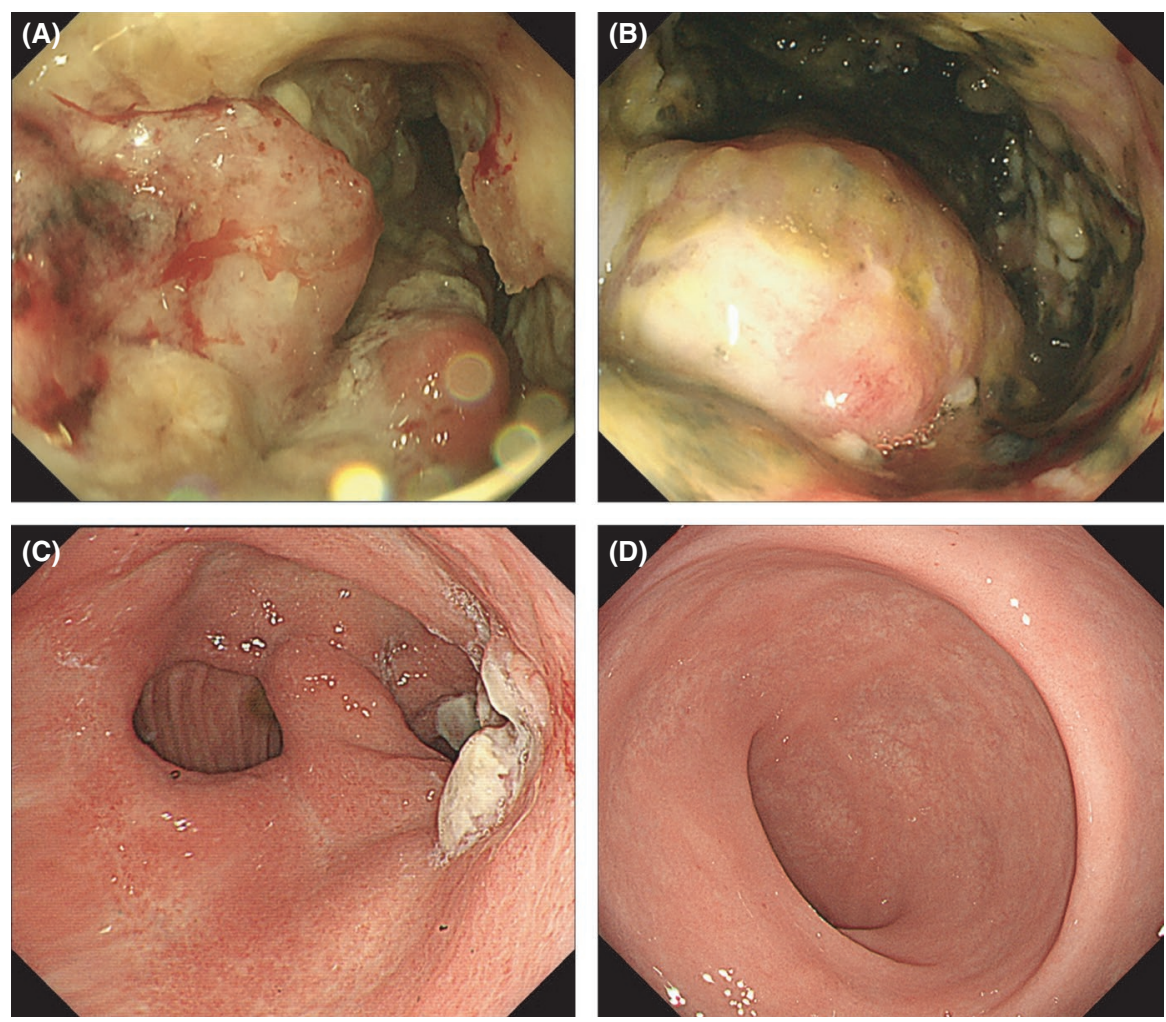

later-line treatment. In this case, oral intake was not improved by first- and second-line treatment; additionally, the patient experienced disease progression. However, oral intake was completely improved with third-line nivolumab monotherapy, and complete tumor response was achieved as observed on imaging studies.
Nivolumab monotherapy is administered for heavily treated gastric cancer according to the ATTRACTION-2 study. However, in that study, the response rate was $11 \%$, and only three patients had a complete response, ${ }^{8,13}$ although patients with complete or partial response had long-term response. ${ }^{13}$ Unfortunately, few patients responded, and hyperprogressive
F IGURE 3 Histology and immunohistochemistry of the gastric mucosal biopsy specimen. (A) Hematoxylineosin stain (low-power field) indicating poorly differentiated adenocarcinoma.

(B) Hematoxylin-eosin stain (high-power field) indicating poorly differentiated adenocarcinoma. (C) Epstein-Barr virusencoded RNA in situ hybridization was negative. (D) Programmed death-ligand 1 staining; the combined positive score $\geq 10$
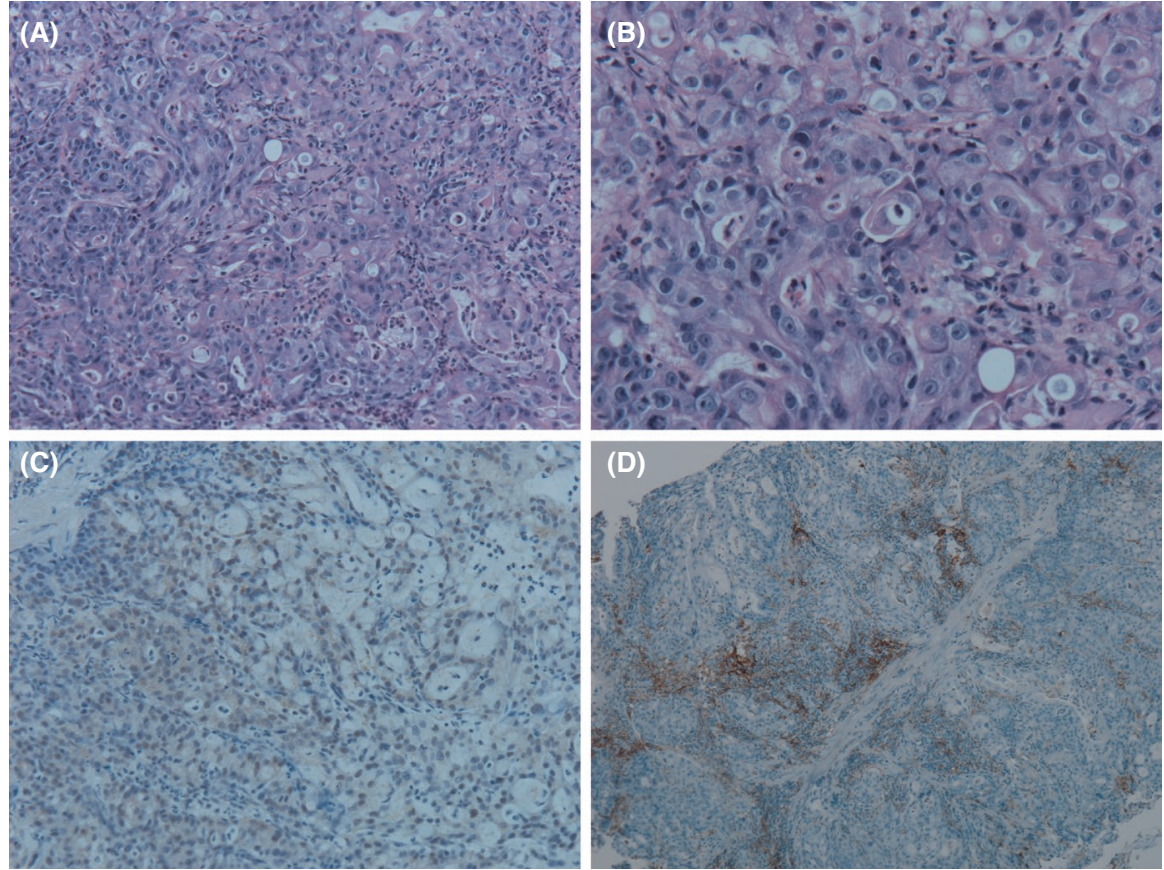
TA B LE 2 Laboratory data at the first administration of nivolumab

\begin{tabular}{lll} 
Hematology & & Normal range \\
\hline White blood cells & $17020 / \mu \mathrm{L}$ & $3300-8600 / \mu \mathrm{L}$ \\
\hline Neutrophils & $92.0 \%$ & \\
Monophils & $3.5 \%$ & \\
\hline Lymphocytes & $4.5 \%$ & \\
\hline Red blood cells & $253 \times 10^{4} / \mu \mathrm{L}$ & $386-492 \times 10^{4} / \mu \mathrm{L}$ \\
\hline Hemoglobin & $7.0 \mathrm{~g} / \mathrm{dL}$ & $11.6-14.8 \mathrm{~g} / \mathrm{dL}$ \\
\hline Platelets & $31.7 \times 10^{4} / \mu \mathrm{L}$ & $15.8-34.8 \times 10^{4} / \mu \mathrm{L}$ \\
\hline Tumor markers & & Normal range \\
\hline CEA & $6.9 \mathrm{ng} / \mathrm{mL}$ & $<5.0 \mathrm{ng} / \mathrm{mL}$ \\
\hline CA19-9 & $52.0 \mathrm{U} / \mathrm{mL}$ & $<37.0 \mathrm{U} / \mathrm{mL}$ \\
\hline Biochemistry & & Normal range \\
Total protein & $4.0 \mathrm{~g} / \mathrm{dL}$ & $6.7-8.3 \mathrm{~g} / \mathrm{dL}$ \\
\hline Albumin & $1.4 \mathrm{~g} / \mathrm{dL}$ & $4.0-5.0 \mathrm{~g} / \mathrm{dL}$ \\
\hline Total bilirubin & $0.2 \mathrm{mg} / \mathrm{dL}$ & $0.3-1.2 \mathrm{mg} / \mathrm{dL}$ \\
\hline AST & $31 \mathrm{U} / \mathrm{L}$ & $13-33 \mathrm{U} / \mathrm{L}$ \\
\hline ALT & $24 \mathrm{U} / \mathrm{L}$ & $6-27 \mathrm{U} / \mathrm{L}$ \\
\hline LDH & $192 \mathrm{U} / \mathrm{L}$ & $119-229 \mathrm{U} / \mathrm{L}$ \\
\hline BUN & $13 \mathrm{mg} / \mathrm{dL}$ & $8-22 \mathrm{mg} / \mathrm{dL}$ \\
\hline Creatinine & $0.41 \mathrm{mg} / \mathrm{dL}$ & $0.40-0.70 \mathrm{mg} / \mathrm{dL}$ \\
\hline Na & $135 \mathrm{mmol} / \mathrm{L}$ & $138-146 \mathrm{mmol} / \mathrm{L}$ \\
\hline K & $4.0 \mathrm{mmol} / \mathrm{L}$ & $3.6-4.9 \mathrm{mmol} / \mathrm{L}$ \\
\hline Ca & $7.4 \mathrm{mg} / \mathrm{dL}$ & $8.7-10.3 \mathrm{mg} / \mathrm{dL}$ \\
\hline & & \\
\hline & & \\
\hline
\end{tabular}

Abbreviations: ALT, alanine aminotransferase; AST, aspartate aminotransferase; BUN, blood urea nitrogen; Ca, calcium; CA19-9, carbohydrate antigen 19-9; CEA, carcinoembryonic antigen; K, potassium; LDH, lactate dehydrogenase; $\mathrm{Na}$, sodium. disease was common. ${ }^{14}$ Many studies have examined predictive factors of the response to ICIs to select patients who may respond to such treatment. Microsatellite instability is one such predictive factor. Janjigian et al reported that the efficacy of cytotoxic drugs was limited among patients with MSI-H gastric cancer. ${ }^{15}$ According to the KEYNOTE-158 study, which was a single-arm phase II trial for MSI-H solid tumors treated with pembrolizumab, the median OS of all patients was 27.8 months, and the median OS of MSI-H gastric cancer patients was not reached. ${ }^{16}$ In the subanalysis of the KEYNOTE-061 and -062 studies, which were phase III trials of second-line and first-line pembrolizumab, respectively, for gastric cancer patients, the median OS of patients with MSI-H gastric cancer who received pembrolizumab was longer than that of those receiving chemotherapy. ${ }^{12,17}$ In the current case, the patient had a durable response to thirdline nivolumab because she had MSI-H gastric cancer. The first- and second-line treatments were not effective, which is consistent with the previous report. The patient has been disease free for 2 years with nivolumab therapy. Therefore, we believe it is important to evaluate the microsatellite instability status before first-line treatment, and if the patient has an MSI-H tumor, the response should be evaluated early during first-line treatment.

PD-L1 and Epstein-Barr virus infection have also been reported to be predictive factors for treatment response to ICIs. ${ }^{18}$ In the KEYNOTE-062 study, 21 (11.5\%) of 182 patients with a CPS $\geq 10$ had MSI-H tumors, whereas 33 (6.5\%) of 506 patients with a CPS $\geq 1$ had MSI-H tumors. ${ }^{17}$ CPS is associated with MSI status, and gastric cancer patients with a CPS $\geq 10$ have sustained response to ICIs.

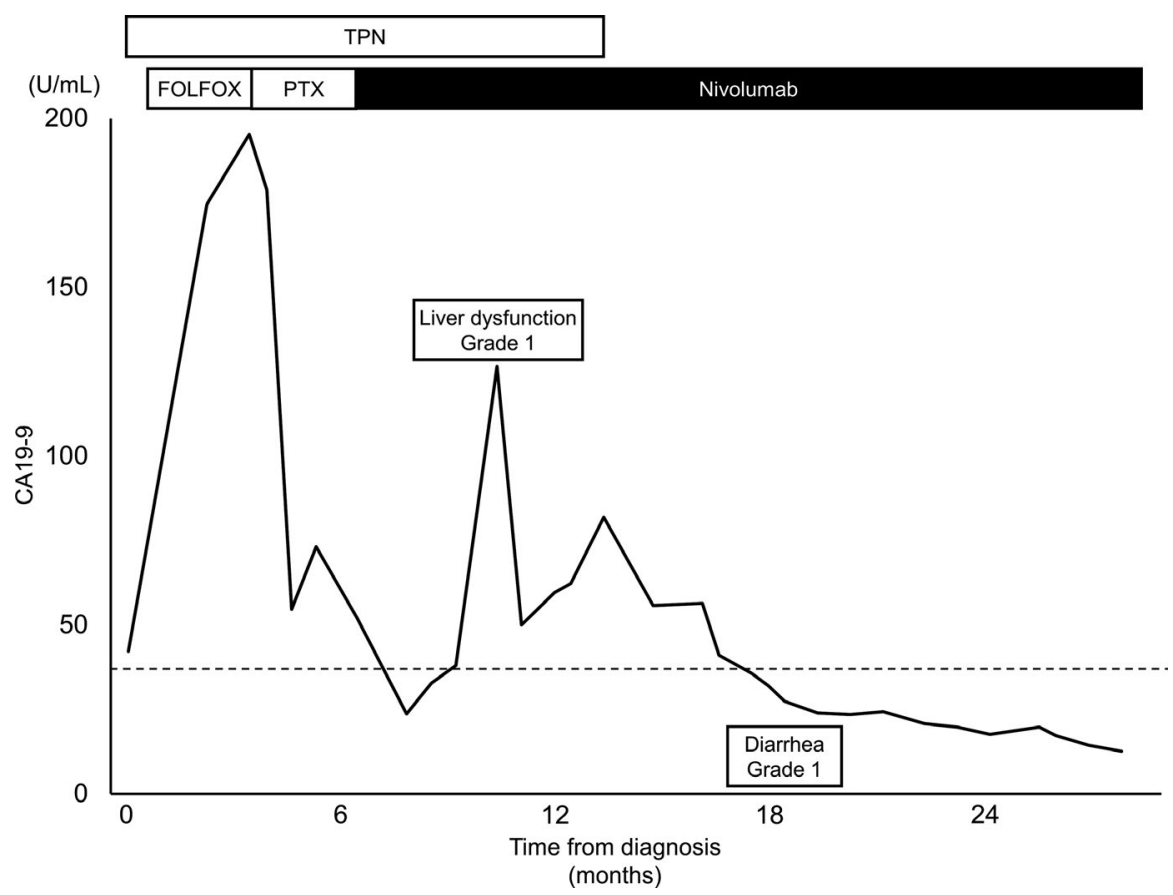

FIG URE 4 Changes in CA19-9 level during the patient's course of treatment. CA19-9, carbohydrate antigen 19-9; TPN, total parenteral nutrition; PTX, paclitaxel 
TA B LE 3 Improvement rate of oral intake with first-line systemic chemotherapy

\begin{tabular}{lllll}
\hline Trials & Phase & Regimen & $\begin{array}{l}\text { Improvement } \\
\text { rate }\end{array}$ & Reference \\
\hline JCOG0106 & III & $\begin{array}{l}\text { 5-FU ci } \\
\text { 5-FU + MTX }\end{array}$ & $41 \%$ & 1 \\
\hline JCOG1108/ WJOG7312G & II/III & 5-FU + LV & $37 \%$ & 2 \\
& & FLTAX & $32 \%$ & \\
\hline Arai et al & retro & 5-FU & $43 \%$ & 3 \\
& & 5-FU + platinum & $64 \%$ & \\
\hline Shitara et al & retro & Any & $40 \%$ & 4 \\
\hline Yukami et al & retro & FOLFOX & $72 \%$ & 5 \\
\hline Osumi et al & retro & mFOLFOX6 & $85 \%$ & 6 \\
\hline Iwasa et al & retro & Any & $33 \%$ & 7 \\
\hline
\end{tabular}

Note: 5 -FU ci, $800 \mathrm{mg} / \mathrm{m}^{2} /$ day on days 1-5, every 4 weeks; MTX +5 -FU, methotrexate $100 \mathrm{mg} / \mathrm{m}^{2}$ and $5-\mathrm{FU}$ $600 \mathrm{mg} / \mathrm{m}^{2}$, every week; Best available 5 -FU, 5-FU ci, or MTX + 5-FU; PTX, $80 \mathrm{mg} / \mathrm{m}^{2} /$ day on days 1,8 , and 15 , every 4 weeks; SP, S- $180 \mathrm{mg} / \mathrm{m}^{2} /$ day on days $1-21$ and cisplatin $60 \mathrm{mg} / \mathrm{m}^{2}$ on day 8 , every 5 weeks; S-1 + PTX iv + PTX ip, S-1 $80 \mathrm{mg} / \mathrm{m}^{2} /$ day on days $1-14$, intravenous PTX $50 \mathrm{mg} / \mathrm{m}^{2}$ on days 1 and 8 , and intraperitoneal PTX $20 \mathrm{mg} / \mathrm{m}^{2}$ on days 1 and 8 ; Bolus 5-FU, $600 \mathrm{mg} / \mathrm{m}^{2}$ on day 1 , every week.

Abbreviations: 5-FU, 5-fluorouracil; ci, continuous infusion; ip, intraperitoneal administration; iv, intravenous administration; MTX, methotrexate; OS, overall survival; PTX, paclitaxel; retro, retrospective study.
Patients with pre-existing autoimmune disease develop irAEs more frequently than patients without autoimmune disease. ${ }^{19,20}$ In this case, our patient had rheumatoid arthritis but did not develop severe irAEs. However, patients should still be closely monitored for irAEs during and after ICI administration.

In conclusion, we report herein the first case of marked improvement of oral intake with third-line nivolumab monotherapy for a gastric cancer patient with insufficient oral intake. This report highlights that ICIs should be administered for MSI-H gastric cancer, regardless of the patient's general condition.

\section{ACKNOWLEDGMENTS}

Published with written consent of the patient.

\section{CONFLICT OF INTEREST}

None declared.

\section{AUTHOR CONTRIBUTIONS}

TO: Collected information for the case and drafted the initial version of the manuscript. YN: Drafted the initial version of the manuscript. KM: Critical feedback and editing of manuscript. WH: Researched references. KM: Critically edited and revised the initial draft of the manuscript with regard to important intellectual content, with a focus on the psychiatric aspects. All authors discussed the case and commented on the manuscript at all stages and provided their final approval of the version to be published in Clinical Case Reports.

\section{ORCID}

Takatsugu Ogata (D) https://orcid.org/0000-0003-1059-5215

\section{REFERENCES}

1. Shirao K, Boku N, Yamada Y, et al. Randomized Phase III study of 5-fluorouracil continuous infusion vs. sequential methotrexate and 5-fluorouracil therapy in far advanced gastric cancer with peritoneal metastasis (JCOG0106). Jpn J Clin Oncol. 2013;43:972-980.

2. Yamaguchi K, Nakajima TE, Boku N, et al. Randomized phase II/III study of 5-fluorouracil/1-leucovorin versus 5-fluorouracil/l-leucovorin plus paclitaxel in gastric cancer with severe peritoneal metastasis (JCOG1108/WJOG7312G). J Clin Oncol. 2019;37:80.

3. Shitara K, Ito S, Sawaki A, et al. Improvement of oral intake following chemotherapy in gastric cancer patients with an inability to eat. Oncology. 2010;79:211-218.

4. Arai H, Iwasa S, Boku N, et al. Fluoropyrimidine with or without platinum as first-line chemotherapy in patients with advanced gastric cancer and severe peritoneal metastasis: a multicenter retrospective study. BMC Cancer. 2019;19:652.

5. Yukami $H$, Terazawa $T$, Goto $M$, et al. Impact of modified FOLFOX-6 for patients with gastric cancer and a gastrointestinal obstruction. Asia Pac J Clin Oncol. 2019;15:e91-e96.

6. Osumi H, Takahari D, Chin K, et al. Modified FOLFOX6 as a first-line treatment for patients with advanced gastric cancer with massive ascites or inadequate oral intake. Onco Targets Ther. 2018;11:8301-8307.

7. Iwasa S, Nakajima TE, Nakamura K, et al. Systemic chemotherapy for peritoneal disseminated gastric cancer with inadequate oral intake: a retrospective study. Int J Clin Oncol. 2011;16:57-62.

8. Kang YK, Boku N, Satoh T, et al. Nivolumab in patients with advanced gastric or gastro-oesophageal junction cancer refractory to, or intolerant of, at least two previous chemotherapy regimens (ONO-4538-12, ATTRACTION-2): a randomised, double-blind, placebo-controlled, phase 3 trial. Lancet. 2017;390:2461-2471.

9. Tomita T, Kitayama Y, Eda H, et al. Therapeutic effect of nivolumab therapy on malignant ascites in the patients with advanced gastric cancer. Gastroenterology. 2019;156:S-310. 
10. Rüschoff J, Dietel M, Baretton G, et al. HER2 diagnostics in gastric cancer-guideline validation and development of standardized immunohistochemical testing. Virchows Arch. 2010;457:299-307.

11. Gulley ML, Tang W. Laboratory assays for Epstein-Barr virus-related disease. J Mol Diagn. 2008;10:279-292.

12. Shitara K, Özgüroğlu M, Bang YJ, et al. Pembrolizumab versus paclitaxel for previously treated, advanced gastric or gastro-oesophageal junction cancer (KEYNOTE-061): a randomised, open-label, controlled, phase 3 trial. Lancet. 2018;392:123-133.

13. Satoh T, Chen L, Kang Y, et al. A phase III study of nivolumab (nivo) in previously treated advanced gastric or gastric esophageal junction (G/GEJ) cancer (ATTRACTION-2): Two-years update data. Ann Oncol. 2018;29:viii206.

14. Aoki M, Shoji H, Nagashima K, et al. Hyperprogressive disease during nivolumab or irinotecan treatment in patients with advanced gastric cancer. ESMO Open. 2019;4:e00488.

15. Janjigian YY, Sanchez-Vega F, Jonsson P, et al. Genetic predictors of response to systemic therapy in esophagogastric cancer. Cancer Discov. 2018;8:49-58.

16. Diaz LA, Le D, Maio M, et al. Pembrolizumab in microsatellite instability high cancers: Updated analysis of the phase II KEYNOTE-164 and KEYNOTE-158 studies. Ann Oncol. 2019;30:v475-v532.

17. Tabernero J, Cutsem EV, Bang Y-J, et al. Pembrolizumab with or without chemotherapy versus chemotherapy for advanced gastric or gastroesophageal junction (G/GEJ) adenocarcinoma: The phase III KEYNOTE-062 study. J Clin Oncol. 2019;37:LBA4007.

18. Kim ST, Cristescu R, Bass AJ, et al. Comprehensive molecular characterization of clinical responses to PD-1 inhibition in metastatic gastric cancer. Nat Med. 2018;24:1449-1458.

19. Danlos FX, Voisin AL, Dyevre V, et al. Safety and efficacy of anti-programmed death 1 antibodies in patients with cancer and pre-existing autoimmune or inflammatory disease. Eur J Cancer. 2018;91:21-29.

20. Abdel-Wahab N, Shah M, Lopez-Olivo MA, et al. Use of immune checkpoint inhibitors in the treatment of patients with cancer and preexisting autoimmune disease. Ann Intern Med. 2018;169:133-134.

How to cite this article: Ogata T, Narita Y, Misawa K, Hosoda W, Muro K. Marked improvement of oral intake with nivolumab monotherapy in a patient with microsatellite instability-high gastric cancer with insufficient oral intake. Clin Case Rep 2021;9:50-56. https://doi.org/10.1002/ccr3.3399 